\title{
ACCION SOCIAL EN LA POSTMODERNIDAD. Ocupación y movimiento por la vivienda en Sevilla
}

\section{SOCIAL ACTION IN THE POSTMODERN ERA. Squatting and struggles for housing in Seville}

\author{
Ibán Díaz-Parra \\ Universidad Nacional Autónoma de México \\ idiaz@igg.unam.mx
}

\section{Resumen:}

A partir del inicio de crisis económica en 2007, el problema y el movimiento por la vivienda en España han cobrado una notable importancia, así como el uso de la ocupación de viviendas vacías por los afectados. Frente al predominio en las últimas décadas de análisis de los movimientos sociales que tendían a poner énfasis en los aspectos subjetivos, el nuevo contexto invita a revalorizar el peso de los aspectos materiales en la movilización social. Este trabajo parte del contraste entre las teorías de la acción social centradas en las clases sociales y la teoría de los movimientos sociales. Los datos cualitativos y cuantitativos provienen de investigación realizada sobre el caso del movimiento por la vivienda en Sevilla y el recurso a la ocupación, antes de la crisis económica, fundamentalmente asociada al movimiento okupa, y después en mayor medida vinculado a las víctimas de desahucios.

Palabras clave: movimientos sociales, urbanismo, vivienda, crisis, movimiento okupa, teoría acción social.

\begin{abstract}
:
Since the start of the economic crisis in 2007, the issue of housing and housing mobilization gained significant importance in Spain as squatting on vacant housing sites increased. While theories of the last decade emphasized "subjective aspects" of social movements, the new context of the crisis invites a reevaluation of the relevance of "material aspects" in social mobilization analysis. Also, this research contrasts social action theories centered on social classes with new social movement theories. Qualitative and quantitative data are provided from research done on the housing movement in Sevilla (Spain) given that before the economic crisis it was fundamentally associated with the squatting movement, and later it became linked to the social fight against evictions.
\end{abstract}

Keywords: social movements, urbanism, housing, crisis, squatting movement, social action theory 


\section{Introducción}

España es uno de los países europeos que se ha visto más afectado por la crisis económica global que se puso de manifiesto en 2007. Tras varias décadas de modernización, crecimiento económico y movilidad social ascendente, el país sufre empobrecimiento y polarización social. Una de las problemáticas que mejor refleja esta situación es la de la vivienda.

En el periodo anterior a la crisis, la construcción fue un elemento fundamental de la economía española. Durante el mismo se acumuló un creciente stock de viviendas vacías y los hogares españoles desarrollaron una fuerte tendencia a la propiedad de sus casas mediante el endeudamiento. Tras la eclosión de la crisis económica, han sido miles los hogares que no han podido seguir pagando su hipoteca y han sido desahuciados.

En los años anteriores a 2007, en los que se gestó la "burbuja inmobiliaria", el "movimiento okupa" era uno de los pocos que realizaba una crítica a la especulación. Este movimiento utilizaba la ocupación de edificios vacíos para realizar sus denuncias, siendo por sus características integrable dentro de lo que desde los años setenta vino a denominarse como nuevos movimientos sociales, orientados a la autogestión y al desarrollo de prácticas culturales y estilos de vida contestatarios. En el contexto de crisis a partir de 2007, la ocupación organizada de viviendas vacías adquirió un nuevo auge. En pocos años, han pasado a ser las asociaciones de hipotecados y las plataformas contra los desahucios las que tienen mayor visibilidad y la ocupación es realizada por familias que pierden sus viviendas. Asimismo, tanto el movimiento como la acción de la ocupación se orientan a conseguir cambios políticos que tengan repercusiones materiales positivas en los agentes que los protagonizan.

Esta investigación sobre movimientos sociales de la vivienda, se formula las siguientes preguntas ¿Los cambios existentes implican un incremento de la importancia de los factores materiales en la movilización? La evolución de los movimientos por la vivienda ¿obliga a revisar la crítica que se le venía haciendo desde la década de los setenta al análisis marxista tradicional sobre acción colectiva?

El trabajo parte de la exposición sintética de los principales aspectos teóricos de dos tradiciones académicas: por un lado, del marxismo en relación a la acción social y, por otro, de la teoría de los nuevos movimientos sociales. En ambos casos se señalan implicaciones en relación al problema urbano.

Seguidamente se construye el análisis caso del movimiento por la vivienda y la okupación en España, concretando en mayor medida el caso de Sevilla. En el mismo se examina el cambio en el peso de los factores objetivo-materiales en relación al surgimiento de la acción social, antes y después del inicio de la crisis económica. Finalmente se valora el ajuste del caso a la teoría, discutiendo las preguntas o hipótesis interpretativas enunciada de partida.

La información a la que se recurre procede de la investigación participante en los procesos de organización y movilización descritos y de la exploración de los archivos generados por la red de Puntos de Información de Vivienda y Encuentro de la Intercomisión de Vivienda del 15M Sevilla, establecida desde principios de 2012. ${ }^{1}$

1 Esta aportación se sitúa en el marco del proyecto de investigación fundamental no orientada CSO2011-23079 del Ministerio de Innovación y Ciencia, con el Dr. Miguel Martínez como investigador principal, al mismo tiempo, su elaboración ha sido permitida por el apoyo del programa de becas posdoctorales del Consejo Técnico de la Investigación Científica de la UNAM (2012). Las referencias teóricas que se incluyen en esta publicación vienen en gran parte de discusiones de su autor con el Dr. José Candón Mena, al que agadezco su colaboración. 


\section{Factores objetivos y teorías de la acción colectiva.}

\subsection{Marxismo y movimiento obrero}

El marxismo clásico parte de una concepción donde la base económica sería la causa de la existencia de la clase, de la conciencia colectiva y de la movilización. El trabajo de Marx se basó en mayor medida en la comprensión de la estructura económica, sin estudiar en profundidad el proceso por el que se formaban las movilizaciones y las organizaciones. Sus anotaciones para establecer una teoría de la estructura social se encuentran en la parte final del tercer tomo de El Capital. Por tanto, nos basamos en autores marxistas posteriores, que sí han desarrollado estas cuestiones, para sintetizar las siguientes claves de la interpretación marxista del problema:

Primero, el marxismo centra su análisis de la acción colectiva en un tipo de sujeto, la clase social, con una identidad generada por su situación material, en concreto por su relación con los medios de producción, con objetivos también materialistas. La hipótesis principal del marxismo respecto de esta cuestión era la tendencia a la polarización en torno a las dos clases fundamentales de la sociedad capitalista: la burguesía y la clase obrera (ver por ejemplo Ossowski, 1972). Consecuentemente, el sujeto de la transformación social que propugna el marxismo es el movimiento obrero (con un peso político indiscutible entre finales del siglo XIX y la primera mitad del XX).

Segundo, la acción colectiva se entiende como consecuencia de la posición de las clases en estructura económica. Así Marx $(1848,1864)$ considera la acción colectiva como resultado de un grupo social que comparte condiciones estructurales y que alcanza una conciencia de las mismas, lo que desemboca en la organización. La conciencia de clase es un elemento esencial sin el cual ni siquiera tiene sentido hablar de clases (como se encargan de recordar insistentemente Dos Santos, 1973, Borja, 1971 y otros autores). No obstante, conciencia de clase y organización de clase se desarrollan en el campo de las posiciones de clase y la coyuntura (situación concreta de la clase en un contexto geográfico y económico), que son las condiciones que permiten su intervención como fuerzas sociales. Las clases intervendrían como fuerzas políticas en formaciones sociales histórica y geográficamente determinadas (Poulantzas, 1976).

Tercero, las relaciones políticas e ideológicas entre clases se encarnan como prácticas materiales en los aparatos del Estado. En principio, el Estado encarna el poder de clase de la burguesía, por lo que el principal objetivo del movimiento social sería la destrucción del Estado burgués y su sustitución por un Estado obrero (Ibídem). Es decir, la lucha tiene una dimensión indiscutiblemente política ${ }^{2}$ en la que el poder estatal tiene una posición central.

Diversos autores clave de la literatura marxista durante el siglo XX, dan mayor importancia a los aspectos ideológico-motivacionales, que en la teoría marxista original quedaban en gran medida relegados a meros epifenómenos de la estructura económica. En este sentido es clave la figura de Gramsci (1949), que atiende a los factores culturales que construirían la "hegemonía" de clase. Este autor y sus análisis son fundamentales dentro de lo que se denomina marxismo occidental, que sería renovado por las teorías de la interacción política y el concepto de los marcos culturales.

En esta línea, Thompson, Hobsbawn y Williams, teorizan la movilización como fruto de las experiencias sociales compartidas por el colectivo, sus tradiciones y formas

2 En el sentido de política pura o política estatal, como una de las posibles dimensiones de la política (Echeverría, 1998). 
de sociabilidad. De estos, el más relevante para el tema aquí tratado es Thompson (2012), el cual desarrolla un importante ataque a las posiciones ortodoxas y/o estructuralistas en el marxismo. La clave de su interpretación de clase está en que esta no existe a partir de sus determinaciones objetivas, sino que es una construcción social. La conciencia de clase se desarrolla en procesos de lucha, en los cuales se forma la clase en sí misma. Por tanto, la lucha de clases tiene primacía causal, haciendo que pueda existir aun cuando uno de los polos de la misma tenga escasa conciencia y sea dudoso como clase. Además, puede surgir de forma similar en distintos momentos y lugares, pero nunca exactamente de la misma forma. Las resistencias no son un reflejo mecánico de la explotación, sino que se producen a partir de elementos culturales propios de cada sociedad (Ibídem, 1989). Estas posiciones tienen gran influencia en pensadores más recientes, como Scott (2003) que se centra en gran medida en los discursos desarrollados por los dominados en diversos contextos, como resistencia a la ideología dominante.

La aportación de Thompson (junto a otros autores, como Raymond Williams) supone una revalorización del papel de la subjetividad en el proceso de conformación de la clase. No obstante, tampoco abandona la perspectiva materialista. La conciencia de clase es la forma en que se expresan ciertas experiencias compartidas, que hacen a algunos hombres actuar y sentir identidad de sus intereses comunes y enfrentados a otros. Esta experiencia viene determinada por ciertas condiciones materiales. No obstante, por sus fuertes ataques al economicismo, existe el riesgo de hacer una interpretación de este autor que lleve a ignorar las condiciones objetivas (advierte Camarero, 2009).

\subsection{Nuevos y novísimos movimientos sociales}

Fuera de la corriente marxista, el surgimiento de los nuevos movimientos de los sesenta y setenta, claramente distinguibles del movimiento obrero clásico, dará lugar a teorías explicativas adecuadas a los nuevos sujetos movilizados. En este contexto, académicos de izquierda realizan fuertes ataques al marxismo, descartando el mecanicismo económico y reclamando la necesidad de atender a la "misteriosa alquimia por la cual un grupo en lucha, colectivo personalizado, agente histórico que se asigna a sí mismo sus propios fines, surge de las condiciones económicas objetivas" (Bourdieu, 1989, p. 32). Otros autores señalan apresuradamente la "superación de la condición proletaria". La polarización y oposición de clases típica del marxismo sería el producto del capitalismo liberal-industrial del siglo XIX en Europa occidental, pero no coincidiría con la realidad del siglo XX (Touraine, 1973, pp. 14-21).

Touraine, Habermas o Melucci son nombres vinculados a la teoría de los nuevos movimientos sociales. Estos autores, sin perder de vista los aspectos estructurales, pondrán énfasis en cuestiones culturales e ideológicas, señalando al mismo tiempo los profundos cambios acaecidos en la sociedad en la segunda mitad del siglo XX. Para Melucci $(1989,1999)$ los nuevos movimientos sociales se derivan de los cambios acelerados en las sociedades complejas, en las que ocurren tres procesos que las diferencian de las sociedades industriales: el peso que adquiere la cuestión de la formación, la existencia de un sistema-mundo interdependiente y la individualización de la sociedad, la multiplicación de las identidades y la desaparición de la conciencia de clase. Los movimientos sociales reflejarán estos rasgos de las sociedades complejas, otorgando un papel central a la información, poniendo las formas de organización como metas, en tanto que relaciones sociales significativas para los actores, y difuminando las esferas pública y privada. Además, para los nuevos movimientos sociales la toma del Estado perderá en gran medida su sentido (Holloway, 2002), 
buscando en su lugar transformar la sociedad mediante la modificación del poder político, desarrollando su actividad principal en el terreno cultural o contracultural. Es decir, en lugar de recursos materiales o poder, se buscaría identidad, autonomía y reconocimiento. De los objetivos directamente políticos se pasa a los de autorrealización personal.

La teoría tratará de entender la influencia de los factores subjetivos en el surgimiento de la movilización. En su análisis de los movimientos sociales, Melucci asume el constructivismo social (Berger y Luckmann, 1998) según el cual la identidad es socialmente construida. Desde este enfoque, critica el dualismo entre las explicaciones de la acción colectiva que enfatizan la importancia de factores estructurales y las que enfatizan el poder de las intenciones situando a los movimientos entre los enfoques objetivistas y subjetivistas. Los actores individuales deben organizarse entre sí para formar la acción colectiva y sus creencias y motivaciones no son productos meramente subjetivos, sino que se forman en el interior de un sistema de relaciones sociales. Los movimientos sociales son pues "construcciones sociales" ya que la acción social es construida y activada por actores que recurren a bienes limitados ofrecidos por el medio ambiente dentro del cual interactúan. La identidad es el resultado de intercambios, negociaciones, decisiones y conflictos entre diversos actores, siendo también socialmente construida. Por ello, para Melucci los movimientos no pueden analizarse sólo como producto de la estructura sino como una interacción de objetivos, recursos y obstáculos, es decir, como orientaciones intencionales dentro de la estructura que provee oportunidades y límites.

Si bien la teoría de los nuevos movimientos sociales sigue atendiendo al marco estructural y al rol de los aspectos materiales en la movilización, puede señalarse que estos últimos desaparecen como principal motivación en favor de factores de carácter ideológico-cultural. Asimismo, de forma evidente, se traslada el foco de atención de las clases populares a una multitud de sujetos e identidades culturales.

Algunos autores señalan que, desde finales de la década de los noventa, los nuevos movimientos adquieren un discurso más inclusivo, abierto y con un carácter progresivamente ciudadanista. Perciben en este proceso el surgimiento de una "política del y" (abierta, agregativa) que se impone a una "política del o" (cerrada, disyuntiva) a la hora de construir protestas o discursos que canalicen el descontento (Calle, 2013). La "política del o" sería propia del movimiento obrero, divididos por intereses, agendas y sectores protagonistas muy segmentados y con una perspectiva antagonista respecto al sistema capitalista. Por su parte, la "política del y" surge con la cultura política de los nuevos movimientos globales. En este sentido, sería notoria la influencia sobre los movimientos juveniles del zapatismo y el movimiento antiglobalización. Asimismo, algunos autores marcan las diferencias entre las movilizaciones generadas en este contexto y las anteriores hablando en algunos casos de "novísimos movimientos sociales" (NsMS) (López y Sánchez, 2005, Pastor, 2006 e lbarra, 2005) o "nuevos movimientos globales" (NMG) (Calle, 2005). Estos novísimos movimientos se caracterizan, por una parte, por la globalidad, no en el sentido territorial, sino por los temas y reivindicaciones que incorporan en contraste con protestas fuertemente tematizadas como las del feminismo o el ecologismo. Una integración que seguiría la línea de corrientes como el ecofeminismo, el ecosocialismo, etcétera. Además, volverían a poner a la economía en primer plano, aunque no ya con la posición central que tenía en el movimiento obrero. 


\subsection{El problema urbano y la acción social}

En la década de los setenta, el estudio de las contradicciones urbanas cobró una fuerza especialmente relevante en las ciencias sociales, en gran medida gracias a la duradera influencia que ejercieron los trabajos de Henri Lefebvre. Desde una perspectiva marxista, Lefebvre (1969) desplazó el foco de la producción a la reproducción y el consumo, abriendo el camino para un fértil campo de análisis. Por lo general, para los autores marxistas, la relación de las condiciones urbanas de reproducción de la fuerza de trabajo, con un aspecto central en la cuestión de la vivienda, con las condiciones de producción, de empleo y de trabajo, sería lo que definiría la problemática urbana. En esta línea, David Harvey (1982) señalaba que la separación entre lugar de trabajo y lugar de residencia implicaría que la lucha del trabajo para controlar las condiciones sociales de su propia existencia se divide en dos líneas de acción aparentemente independientes. La primera, localizada en el lugar de trabajo, es sobre la tasa de salario, la cual provee de poder de consumo de bienes. La segunda en el lugar de residencia, contra las formas secundarias de explotación y apropiación representadas por el capital mercantil, la propiedad de la tierra y similares.

El hecho de que las luchas encontraran el Estado local como interlocutor y adversario proporcionaría además las condiciones para que estas alcanzasen una dimensión política (Topalov, 2006). Para Castells (1974), la naturaleza contemporánea del problema urbano procede de las conquistas sociales y políticas del movimiento obrero (vivienda, servicios, sanidad, cultura etc.). Estas necesidades colectivas e integrales entrarían en contradicción con el carácter privado y parcelario de los agentes económicos. Como consecuencia el consumo colectivo se convertiría en sector deficitario y objeto permanente de reivindicación. Aunque la primera etapa de Castells se sitúa dentro del paradigma del estructuralismo marxista, posteriormente su posición va cambiando, negando el carácter de clase de, por ejemplo, los movimientos vecinales. Desde la década de los ochenta sus planteamientos coinciden en mayor medida con el paradigma de los nuevos movimientos sociales (Castells, 1983).

Por su parte, Harvey (1985), señalaba en principio que las tendencias a la diferenciación residencial en la ciudad tendían a crear conciencia de comunidad en lugar de conciencia de clase, un hecho que sería incluso promovido por los aparatos del Estado, reforzando la segregación para dificultar la organización de clase. No obstante, más adelante, cuando vincula los movimientos de base amplia al espacio, utilizando la teoría del particularismo militante de Raymond Williams, parece situar los sentimientos solidarios de comunidad y la conciencia de clase en diferentes escalas de abstracción-concreción que no serían incompatibles entre sí. Esta teoría sostiene que toda acción o estrategia política parte de grupos sociales que desarrollan su visión política en contextos históricos y geográficos determinados, necesitándose de instituciones mediadoras entre lo particular y lo universal para generar movimientos amplios, como el movimiento obrero (Harvey, 2002). Otro geógrafo urbanista relevante que ha ido modificando sus posiciones es Edward Soja (2001), que frente a los análisis de clase expone la fragmentación sociocultural de la ciudad contemporánea, fruto en parte de los cambios en el modelo económico capitalista. Los movimientos sociales que describe este autor, netamente post-marxista, son micromovimientos volcados en lo local y en la comunidad.

En el estudio del problema urbano y su relación con la acción social, por lo tanto, entre las décadas de los setenta y noventa, la corriente crítica pasa también de explicaciones estructuralistas, centradas en las necesidades materiales y en la clase social, a un énfasis en la fragmentación cultural de la sociedad del capitalismo tardío. No 
obstante, autores como David Harvey mantienen posiciones materialistas, al tiempo que integran las críticas propias del giro cultural en las ciencias sociales.

\section{El marco del problema de la vivienda en el caso español}

A nivel global, los cambios en el modo de regulación del capitalismo a partir de la década de los setenta han tenido un efecto notorio sobre el medio urbano. Este ha sido diverso, aunque han tenido especial relevancia los cambios en el rol del Estado, la financiarización de la economía y los cambios en la estructura ocupacional (Amin, 1994). El Estado español no es una excepción, y al mismo tiempo cuenta con ciertas particularidades reseñables, dado que, si bien la desregularización financiera y la retirada del agente público del mercado de la vivienda han generado burbujas inmobiliario-financieras prácticamente en todo el mundo, su importancia ha sido especialmente significativa en este caso. Algunas de las características más relevantes del problema urbano en el régimen posterior a La Transición son el desarrollo de burbujas inmobiliario-especulativas acompañadas del incremento del stock de viviendas vacías, la especulación con los centros urbanos y la polarización social respecto del problema del acceso a la vivienda.

\subsection{Desregularización financiera e hiperdesarrollo de la construcción}

El capitalismo posterior a la crisis de la década de los setenta, que ha tendido a recibir el adjetivo de post-fordista, tiene algunas características bien conocidas que aparecen de forma ejemplar en el caso español. El régimen resultante de la crisis del fordismo apela a la flexibilidad, se caracteriza por niveles sumamente intensos de innovación, por la emergencia de nuevos mercados y por la desregularización financiera y la complejización de los instrumentos de crédito (Harvey, 1990, pp. 184-185). Esto promovería lo que ha venido a denominarse "oleada de Inversión Extranjera Directa" que en España se ve potenciada por la entrada en la Comunidad Económica Europea (VVAA, 2007, p. 201). En relación a esto, otro aspecto que adquiere relevancia es lo que Harvey (1973 y 1982), siguiendo a Lefebvre, denomina segundo circuito de extracción de plusvalor, basado en la especulación con los derechos de propiedad y en las inversiones en capital fijo como refugio de capitales ante la caída de la tasa de ganancia. Una solución espacial que junto con el crédito y las finanzas conseguiría amortiguar temporalmente las tendencias del capitalismo a la crisis.

En el caso de España estas cuestiones alcanzan una importancia enorme, especialmente por el hiperdesarrollo del sector de la construcción orientado a la vivienda. Esta realidad no se entiende sin referir el elevado peso de la propiedad frente al alquiler, tendencia que se generó en la década de los sesenta y setenta bajo la dictadura franquista. En este periodo se da una importante inversión de capital público en la construcción de vivienda. Primero construcción directa de alojamientos para las clases populares, después subvención a agentes privados para rentabilizar la construcción de alojamientos para familias que, de otra manera, no podrían entrar en el mercado libre (Capel, 1983). A esto se le sumó la legislación sobre alquileres que generaba condiciones ventajosas para los inquilinos, pero desincentivaba a los propietarios a invertir en este mercado (Lasarte Alvarez, 1996). Esto tiene diversas explicaciones. Por un lado, el acceso a la vivienda supuso una pieza fundamental de la paz social tras la Guerra Civil española y de la creación de una cierta clase media local. Esta voluntad queda ejemplificada en la famosa frase "queremos un país de propietarios y no de proletarios" del Ministro de Vivienda entre 1957 y 1960, José Luis Arrese. Por otro lado, fue parte de la creación de una demanda efectiva median- 
te salarios indirectos en el contexto fordista. Esta cuestión, en combinación con el inicio de la urbanización del litoral mediterráneo enfocada al turismo extranjero, condujo a la creación de un gigantesco mercado de la vivienda que alcanzaría un peso inusitado desde la segunda mitad de los años ochenta. A principio de la década de los noventa el $80 \%$ de los hogares del Estado eran propietarios.

En el periodo democrático entraron en juego las reformas propias del contexto postfordista. En primer lugar se produjo la liberalización del mercado hipotecario y la privatización de la banca pública. El Estado dejó progresivamente de invertir en vivienda y fue sustituido, en su papel de generar una demanda solvente, por el libre mercado mediante la facilitación del crédito. La entrada de España en la Comunidad Económica Europea desembocó en el primero de dos fuertes ciclos inmobiliarios alcistas altamente especulativos. El primero entre 1986 y 1992, durante el cual España se convirtió en uno de los principales receptores de inversión extranjera directa a nivel mundial (VVAA, 2007 y Naredo, 1998), al que siguió un período de estancamiento de los precios hasta llegar a 1997, donde se produjo el nuevo despegue hasta el estallido de la burbuja de especulación y deuda en 2007. Este periodo coincidió con un elevado crecimiento económico del país y una reducción notable de las tasas de desempleo. Al mismo tiempo, se acumuló un stock de viviendas vacías cercano a los 3,5 millones (INE, Censo de Población y Vivienda, 2011).

Existe un cierto consenso sobre las causas generales de estos ciclos y del elevado peso de la construcción en el caso español (ver Rodríguez y López, 2011, Marsal y Vilanova, 2013 o Fernández y Cruz, 2013). En primer lugar, el mantenimiento de bajos tipos de interés que da pie a un fuerte endeudamiento de los hogares y las empresas, sosteniendo el crédito tanto la oferta como la demanda de vivienda. En segundo lugar, la constitución del sector inmobiliario y de la construcción como primera industria nacional (junto al turismo), permitiendo periodos de elevado crecimiento económico y bajo desempleo (que a su vez incentivaría la demanda). En tercer lugar, el mantenimiento del apoyo estatal al sector privado de la construcción mediante una variedad de fórmulas. En cuarto lugar, la entrada de inversión extranjera directa en activos inmobiliarios. Por último, el desarrollo de la vivienda como bien de inversión y especulación. Como ejemplo, la revalorización multiplicó por 3,5 el valor del patrimonio nominal de las familias durante el último periodo alcista (Naredo, Carpintero y Marcos, 2008).

\subsection{Vuelco sobre la ciudad consolidada del urbanismo y gentrificación}

Otra de las características fundamentales del capitalismo posterior a la crisis del petróleo es la nueva dimensión e importancia que adquiere lo local. En las políticas locales ganan importancia una serie de prácticas de fomento del desarrollo económico, implementadas a partir de la colaboración del agente público y los agentes privados (Amin, 1994, Jessop, 1995 o Goodwin y Painter, 1996). Algunas de las estrategias más recurrentes han sido las dirigidas a la renovación urbana de centros históricos o enclaves industriales dentro del centro urbano, combinado con la creación de prestige proyects, flagships y otras fórmulas (Amin, 1994). Harvey (2007) señala como estas políticas tienden a centrarse en el lugar en vez de en el territorio. El territorio sería el ámbito de la planificación racional, mientras que en los proyectos estratégicos del urbanismo emprendedor, se tiende a la construcción de lugares (centros cívicos, museos, plazas) confiando en un efecto sobre el entorno que es muy cuestionable en la escala regional.

Bajo esta influencia, en la década de los ochenta se desarrollan en las grandes ciudades españolas todo un conjunto de planes que proponen una vuelta a la ciudad consolidada. En el contexto de las burbujas inmobiliarias se interviene sobre los prin- 
cipales barrios históricos y viejas zonas industriales, que habían sufrido una fuerte decadencia durante las décadas anteriores y estaban habitados fundamentalmente por clases populares en edificaciones deterioradas, con una elevada proporción de ellas vacías y en estado de abandono. Aquí, las administraciones locales desarrollaron una estrategia de intervención sobre el espacio público y construcción de flagships que generó un efecto contagio sobre la iniciativa privada, que empezó a invertir en la rehabilitación o redesarrollo de la edificación (Tomé, 2007 y Fernández Salinas, 1994). Esto, unido a algunas reformas legales, como la liberalización de los alquileres en 1985, dio lugar a fuertes procesos de gentrificación ${ }^{3}$ entre la década de los noventa y el estallido de la burbuja inmobiliaria, siendo bastante conocidos los casos de Barcelona (Sargatal, 2003) o Sevilla (Díaz Parra, 2009).

\subsection{Dualización del mercado de la vivienda y fragmentación de la problemática}

Frente a la problematización del consumo de vivienda por la clase obrera, que predominaba todavía en los setenta, en el contexto postfordista se pone de relieve una progresiva fragmentación de los mercados, relacionada con los cambios culturales y económicos (Harvey, 1991, Soja, 2001). En el caso español, durante el siglo XX y en apenas tres generaciones, la sociedad pasa de una estructura social rural, a una industrial y, finalmente, a una postindustrial. Durante las décadas de los ochenta y noventa, el crecimiento económico implica la consolidación de una amplia clase media cualificada en el sector servicios y propietaria, aunque también la aparición progresiva de la precariedad laboral, que afecta especialmente a la juventud (Tezanos, 1984 y 2002).

Desde finales de los ochenta, en España, el problema de la vivienda podría calificarse de poliédrico, en la medida en que afectaba a grupos diversos de diferente manera. Desde finales de los setenta, ya se percibía una dualización del mercado de la vivienda, con una clase media que suponía una demanda solvente y estratos sociales que no podían acceder al mercado y que dependían de alojamientos subvencionados, al mismo tiempo que se empezaba a generar un stock de viviendas vacías (Capel, 1983). Esta dualización del mercado habría ido empeorando en las siguientes décadas, haciéndose especialmente notoria en el siglo XXI, ante la realidad de que las familias jóvenes no podían acceder a la compra de vivienda por su elevado precio, al mismo tiempo que el patrimonio de las clases medias se incrementaba y los alojamientos vacantes seguían aumentando (Díaz, 2003 o Colau y Alemany, 2012). A esta cuestión cabe añadírsele: la forma diferencial en que el problema de la vivienda pasa a afectar a los grupos populares que seguían habitando en los centros urbanos en régimen de alquiler, la cuestión de la afluencia de población inmigrante extranjera desde la década de los noventa y su relación con formas de alojamiento precario o la pervivencia de la infravivienda en algunos sectores marginados de la periferia obrera de las ciudades. Siendo éstas últimas unas problemáticas que en general le resultaban ajenas a una clase media que había adquirido un peso importante en la estructura social.

\subsection{El hundimiento}

Los periodos alcistas habían provocado una fuerte dependencia del sector de la construcción, millones de viviendas sin uso y unos activos inmobiliarios terriblemente sobrevalorados. En torno al cambio de siglo, la media de viviendas construidas

3 Aunque el concepto de gentrificación y su contenido están sujetos a controversias, una definición bastante clara y utilizada es la que ofrece Clark (2005), entendiendo el fenómeno como un cambio en los usuarios del suelo, de tal manera que los nuevos tienen mayor estatus económico que los anteriores, mediando la reinversión del capital fijo. 
anualmente superaba las 600.000 un número que no estaba justificado en absoluto por la constitución de nuevos hogares y el 15\% de la población se encontraba ocupada en la construcción, un número notablemente superior en Andalucía y en otras regiones costeras (Fernández y Cruz, 2013 y Marsal y Vilanova, 2013).

La crisis financiera internacional supuso la contracción del crédito, lo que afectó en primer lugar a este sector clave de la economía española. Aquí empieza la destrucción del empleo, la caída de la demanda y la generación de un efecto pobreza. El contagio de la destrucción de empleo a otros sectores ha hecho que el país llegue a superar los 6 millones de parados, con unas tasas de paro cercanas al $30 \%$ y por encima del 37\% en Andalucía (EPA, primer trimestre, 2013, INE). Además, la caída de los precios de la vivienda, enfrenta a las familias con los problemas de endeudamiento asumidos en los años anteriores. La combinación de desempleo, desplome de los precios inmobiliarios y una legislación inmobiliaria que no admite la dación en pago deja a las familias hipotecadas sin su vivienda y con deudas elevadísimas para con las entidades de crédito.

En 2012 acontecieron algo más de 100.000 desahucios en España. Esto ha implicado que en algunos trimestres la cifra de desahucios diarios superara el medio millar (ver Estadísticas Judiciales, Consejo Superior del Poder Judicial de España). Además, el carácter raquítico del mercado de alquiler generaliza el problema de la vivienda, más allá de la cuestión del endeudamiento. Todo esto supone pauperización de la clase media, aunque es la clase obrera la que sufre en mayor medida la crisis, puesto que la destrucción de empleo se ha cebado con la construcción y con la industria.

\section{Del movimiento okupa al $15 \mathrm{M}$ y el movimiento por la vivienda}

\subsection{El movimiento okupa}

La ola de movilización de 1968, que suele señalarse como un punto de inflexión en el paso del movimiento obrero clásico a la cultura de los nuevos movimientos sociales, tuvo en España una repercusión más limitada que en el resto de Europa occidental. Por otro lado, en la lucha contra la dictadura desarrollada durante la década de los setenta, siguió teniendo un peso notable el movimiento sindical y obrero. Posteriormente, la llegada de la democracia y de los partidos de centro-izquierda al poder, resultó en la desmovilización y en la progresiva cooptación de las organizaciones obreras, tanto de los sindicatos como de las asociaciones vecinales, que se integraron progresivamente en las instituciones.

En respuesta a la citada institucionalización, las movilizaciones de las generaciones más jóvenes (que no habían participado en el proceso de transición de la dictadura a la democracia liberal) comenzaron a desmarcarse de la tutela de los partidos políticos de izquierda y de las instituciones del movimiento obrero, entrando progresivamente en el mundo de los nuevos movimientos sociales reinante en Europa. Así, los ciclos de movilización fueron adquiriendo un carácter fuertemente ideologizado al tiempo que crítico con el obrerismo. Algunos movimientos consiguieron mantener una base más o menos amplia y un cierto respaldo social, especialmente el movimiento estudiantil o las protestas contra el servicio militar obligatorio, mientras que otros se retiraron de la política institucional, con un carácter cada vez más identitario e incluso marginal, una vez desaparecidos los cauces de comunicación entre la iz- 
quierda radical y las masas populares (posibles casos de la acción antifascista y del movimiento okupa).

El movimiento okupa en España parte de la influencia de las experiencias desarrolladas con carácter previo en países como Alemania, Reino Unido e Italia (Pruijt, 2003 y Martínez-López, 2011). La práctica de la ocupación de centros sociales y viviendas se extendió por todo el territorio estatal entre finales de la década de los ochenta y principios de la de los noventa. Los principales epicentros se localizaron en Madrid y, especialmente, en Barcelona. También se darían experiencias similares en muchas otras ciudades, como Sevilla o Valencia. No obstante, solo en Barcelona el fenómeno adquirió unas dimensiones y una influencia social relevantes y duraderas.

Las ideas políticas de este movimiento basculan entre cierto tipo de anarquismo, que se desvincula de las estrategias sindicales del comunismo libertario, y un autonomismo de importación que se perfila claramente en la Barcelona de finales de los ochenta, con experiencias similares en la Coordinadora de Colectivos Lucha Autónoma de Madrid y el Kasal Popular de Valencia. Aquí la autonomía habría supuesto un cierto eclecticismo entre los colectivos que procedían de la izquierda radical y los colectivos de tradición más puramente anarquista (Adell y Martínez-López, 2002: 135).

El contenido real del movimiento, más que en la teoría política, se encuentra en sus formas organizativas descentralizadas y en sus prácticas fundamentadas en la acción directa. La crítica al devenir del movimiento obrero, empuja además a situarse en un escenario de confrontación con la administración, donde las posibilidades de negociación son descartadas en principio. La ocupación de centros sociales constituiría una herramienta fundamental, tanto para el movimiento okupa como para los "nuevos movimientos sociales" en general (Martínez-López, 2007). Es en este contexto cuando la "okupación" va adquiriendo características de identidad cultural, con unos códigos muy definidos. Así, algunos autores podían afirmar a principios del siglo XXI que el fenómeno okupa suponía "la puesta en práctica de la reproducción de la vida cotidiana a través de la convivencia diaria en las casas o centros sociales autogestionados", una "utopía contracultural" y una "subcultura dentro de la subcultura juvenil” (Adell y Martínez-López, 2004: 179-182) en la que se colectiviza la cultura y la existencia a través de la autogestión del espacio con toda una serie de códigos asociados a la reutilización de los edificios y a la filosofía del "hazlo tú mismo", pasando por el reciclaje de alimentos y objetos desechables (Adell y Martínez-López, 2004 o Dieste y Pueyo, 2003).

Se produce un proceso de construcción y legitimación de tipos de "identidad colectiva diferenciada, en definitiva de sujetos colectivos que se constituyen a partir de reivindicar positivamente su propia diferencia, incluso su estigmatización" (Domínguez, Martínez-López y Lorenzi, 2010: 11). Un caso ejemplar por lo tanto para la teoría de los nuevos movimientos sociales.

Las primeras ocupaciones públicas en Sevilla, adscritas a este movimiento, se desarrollan entre finales de los años ochenta y principios de los años noventa, siendo especialmente relevante el centro social okupado y autogestionado (CSOA) Cruz Verde, entre 1991 y 1995 . Este ciclo de protestas tiene su epicentro en la campaña contra la Exposición Universal que conmemoraba los 500 años del descubrimiento y colonización de América. Asimismo, es destacable el peso de las campañas desarrolladas a nivel estatal, especialmente del antimilitarismo, así como la introducción a través de los centros sociales de estéticas y planteamientos ideológicos como el ecologismo, el feminismo o la teoría queer. Es además un movimiento con unas pautas de localización claramente definidas. Las principales ocupaciones se producen en un 
centro histórico que, todavía en estas fechas, se encuentra en una clara situación de declive, y dentro de este, en los espacios con mayor degradación social y urbanística (San Luis o San Bernardo) y con una fuerte carga simbólico-cultural (Alameda de Hércules) (VVAA, 2006).

En la segunda mitad de los noventa, algunas de las campañas más potentes de los movimientos sociales españoles irían perdiendo fuerza (siendo determinante la desaparición del servicio militar obligatorio), con lo que se produciría un importante vuelco de energías sobre los centros sociales. Al mismo tiempo, el movimiento sufre el endurecimiento de las leyes contra la ocupación y una estigmatización generada por los medios de comunicación (Adell, 2007: 26 y Adell y Martínez-López, 2004). Asimismo, en torno al cambio de siglo, se produce el fuerte influjo del movimiento antiglobalización y un cierto giro ciudadanista de la parte del movimiento más influida por el zapatismo y por el nuevo operaismo italiano, que flexibiliza sus posiciones respecto a las posibilidades de negociación con la administración e institucionalización del movimiento (Sguiglia y Fernández, 2008). Estas cuestiones afectan de manera desigual a distintos territorios. Así, mientras en Barcelona el movimiento se mantiene fuerte, en Sevilla, tras múltiples desalojos y varias ocupaciones fallidas, los centros sociales ocupados desaparecen del panorama público entre 1996 y 2001. Entre 2001 y 2007 se establece como referencia el CSOA Casas Viejas. Aunque gestionado por un colectivo de orientación anarquista las posiciones políticas se alejan progresivamente de los planteamientos anarcosindicalistas, y por lo tanto obreristas, siendo además reconocibles todos los códigos culturales propios del fenómeno okupa. Algo ampliable al caso del CSOA Sin Nombre, ocupado en 2005. En 2007 se desaloja Casas Viejas, acontecimiento que tiene una gran visibilidad debido a que la policía encuentra una fuerte resistencia, algo excepcional en la ciudad (Agudo, 2010). No obstante, las ocupaciones de centros sociales continúan hasta la fecha, aunque con una menor longevidad media, primero el CSOA Fábrica de Sombreros (2008-2009) y luego el CSOA La Huelga (2010-2012) (ver figura 1).

Figura 1. Fachada del CSOA La Huelga.

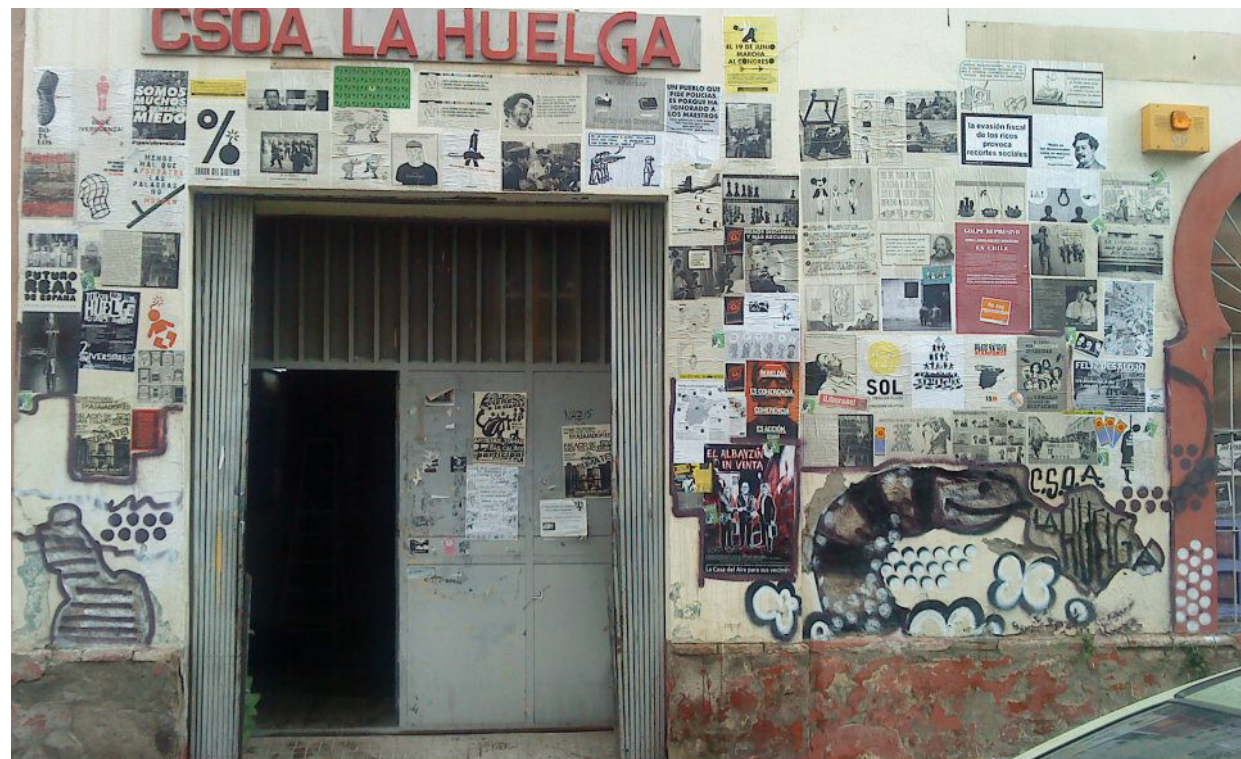

Fte: Anónimo 


\subsection{Centros ocupados y espacio urbano}

La forma que adopta el fenómeno okupa en Sevilla y el Estado español tiene un factor claro y determinante en el contexto en que se desarrolla. La ocupación urbana desde finales de los ochenta encuentra un marco urbano propicio, debido a la creación de un enorme superávit real de viviendas, con los sucesivos ciclos inmobiliarios especulativos, y a la reestructuración de los centros históricos y áreas industriales en declive. En este periodo se llegan a alcanzar cifras inverosímiles de viviendas vacantes (el 14\% del parque total según el Instituto Nacional de Estadística). Estos elementos proporcionan la materia prima y el entorno escénico en el que se desarrolla la ocupación como denuncia de la especulación, configurada como un fenómeno juvenil donde tiene mayor peso la ocupación de centros sociales que de viviendas (Martínez López, 2003).

Por otro lado, en el contexto de estos ciclos alcistas, se produce la reestructuración definitiva de los centros históricos y las viejas áreas industriales obsoletas encajonadas en la ciudad consolidada. En la década de los ochenta e incluso en los noventa, gran parte de los centros históricos permanecían todavía en un estado de extremo abandono concentrando gran parte de los alquileres y las viviendas vacías de las grandes ciudades, así como unas estructuras edilicias faltas de conservación. Al mismo tiempo, una buena parte de los espacios industriales próximos a la ciudad histórica seguían pendientes de ser recualificados. Estos espacios ofrecen oportunidades inmejorables, tanto para la ocupación, por la amplia oferta y por la existencia de estructuras especialmente adecuadas para su uso colectivo (fábricas, naves), como para la denuncia de la especulación, ante la evidencia de los potentes flujos de inversión y desinversión en diferentes frentes de la ciudad que acabarían produciendo la gentrificación y el desplazamiento. En este contexto, se desarrollan ocupaciones dirigidas a frenar la decadencia de los edificios (y del barrio) mediante su ocupación y rehabilitación parcial o a frenar el desalojo de inquilinos pobres (algunos ejemplos están recogidos en Díaz Parra, 2008).

La desvalorización y decadencia demográfica de este tipo de sectores urbanos ha permitido la conformación de enclaves socioculturales alternativos. En Lavapiés, Gracia o la Alameda ha sido evidente como los espacios okupados se han apoyado en este tipo de entornos, generándose comunidades militantes muy identificadas con el sector urbano concreto. La vinculación de estas zonas al fenómeno okupa se produce de forma previa y paralela a los procesos de recualificación y aburguesamiento residencial, de tal manera que el avance los mismos habría supuesto la eliminación de las oportunidades materiales y el desplazamiento de las iniciativas de okupación, o al menos una limitación de las mismas, y coincide con la decadencia del movimiento en la primera década del siglo XX.

\section{3. "15M" y nuevo movimiento por la vivienda}

En 2011, en el plano estatal, surge el movimiento 15M que supondrá un punto de inflexión en la respuesta social contra la crisis e impulsará de forma determinante las luchas locales en todo el país. Como es bien conocido, las manifestaciones masivas convocadas por las redes sociales acabaron en ocupaciones indefinidas de las plazas centrales de las principales ciudades del Estado. Si bien inicialmente el 15M plantea reivindicaciones globales en torno a la mejora de la democracia y críticas a la clase política ${ }^{4}$, pronto las asambleas convergerán con las preocupaciones materiales de la población. Enlazando con la crítica al sistema de democracia representativa, el

4 Ver: [http://www.democraciarealya.es/documento-transversal] 
movimiento encontró en el vecindario el espacio natural de actividad, descentralizándose en pequeñas asambleas. En los barrios, las grandes reivindicaciones políticas se encontrarán con las problemáticas locales y concretas, presentándose con mayor urgencia el tema del paro y la vivienda. Respecto de esta última, dos prácticas resultan especialmente relevantes, la paralización de desahucios y la ocupación de edificios abandonados.

Desde un primer momento, las asambleas de barrio sirvieron para contactar con los amenazados por los desahucios, permitiendo una relación directa con la víctima o una deseable participación de la misma. La organización de resistencias frente a los desalojos, supondría un salto cualitativo importante, permitiendo utilizar la fuerza y la legitimidad acumulada para luchar contra lo que se perciben como injusticias perpetradas contra la población y obteniendo resultados prácticos ${ }^{5}$. Aquí el movimiento 15M alimentó en gran medida a la Plataforma de Afectados por la Hipoteca (PAH), una organización cuyo origen se encuentra en el movimiento por la vivienda de 2006 pero que ganaría especial relevancia en el nuevo contexto de 2011. A nivel estatal el $15 \mathrm{M}$ se aliará con la PAH para frenar el primer desahucio de esta nueva ola de movilización en Madrid, en la jornada del 15 de junio de 2011. En esa semana, la desobediencia civil frustró ocho órdenes de desalojo de viviendas en varias ciudades ${ }^{6}$ Esta práctica se difundiría por todo el Estado en los dos años siguientes y hasta la actualidad.

Por otro lado, desde un principio, en algunas ciudades, los centros sociales del movimiento okupa habían asumido un cierto papel apoyando al movimiento a un nivel fundamentalmente logístico (caso al menos de Madrid y Málaga). Sin embargo, el $15 \mathrm{M}$ empezaría a crear sus propios espacios de referencia a través de la toma de edificios vacíos, evidenciándose, en algunos casos, los intentos de sustitución de la plaza como espacio geográfico común y de referencia a escala de ciudad, casos de Cádiz (Valcárcel) y Madrid (Hotel Madrid). El empleo de la palabra "toma" o "recuperación" frente al de "okupación" denota la intención de asumir la imagen del 15M como identidad estratégica, frente a la estigmatizada fórmula "okupa".

Las primeras ocupaciones de Madrid, frustradas de forma temprana por sucesivos desalojos, empezaron a enlazar con la táctica de intervenir sobre los desahucios. Las ocupaciones realizadas para realojos de familias desahuciadas empezarían a proliferar en 2012. Tras una primera oleada de ocupaciones vinculadas al 15M (en Madrid, Barcelona, Zaragoza, Cádiz y Sevilla), las ocupaciones más recientes de centros sociales muestran la progresiva popularización del movimiento y su afianzamiento en los barrios. Este es el caso del "Banco Güeno", ocupado en Málaga en 2012, y "La Soleá", en Sevilla en 2013, ambos localizados en barrios obreros periféricos de viviendas públicas y con una voluntad de intervenir sobre los problemas sociales de estas zonas.

\subsection{La Intercomisión de vivienda de Sevilla}

Inicialmente, desde los espacios militantes de Sevilla no se prestó mucha atención a la primera movilización estatal del 15 de mayo de 2011, que dio origen al movimiento. Aun así, las organizaciones previas y las tradiciones activistas de los movimientos

5 Para el caso de Sevilla ver: http://estrecho.indymedia.org/sevilla/noticia/paralizado-un-desahucio-torreblanca-sevilla o http://www.elcorreoweb.es/sevilla/136012/vecinos/torreblanca/logran/ frenar/desahucio.

6 Público, 18-06-2011, "Los indignados se lanzan al rescate de los desahuciados". [http://www. publico.es/espana/382602/los-indignados-se-lanzan-al-rescate-de-los-desahuciados] 
sevillanos se encontraron en las asambleas de barrio con una nueva generación de agentes movilizados. Una de las estructuras informales más significativas que se creó en este contexto fue la Intercomisión de Vivienda, que unió a las comisiones de vivienda de las distintas asambleas de barrio.

En este espacio organizativo, con los nuevos activistas surgidos de las manifestaciones masivas, confluyeron militantes significados del movimiento de inquilinos, del movimiento okupa, de la coordinadora de Barrios en Lucha y de las asambleas por la Vivienda Digna a nivel local. Asimismo, desde un principio, se integraron las principales organizaciones que habían trabajado la cuestión habitacional en la década anterior. Desde su inicio, la Intercomisión de Vivienda resultó un espacio de coordinación de la mayor parte de la militancia sevillana en torno a la cuestión de la vivienda.

En Sevilla, la Intercomisión de Vivienda realizó un primer acto público con una convocatoria de manifestación contra los desahucios en octubre de 2011. La misma acabaría con la ocupación del Mercado Provisional de la Encarnación situado justo al lado de la plaza de "Las Setas" donde estuviera la acampada sevillana del movimiento $15 \mathrm{M}$. Sin embargo esta ocupación fue desalojada de forma relativamente rápida, sin dar tiempo a hacer un uso real del espacio. Por otro lado, el movimiento en Sevilla había empezado a convocar concentraciones para parar desahucios desde julio. A partir de octubre esta actividad pasó a organizarse directamente desde la Intercomisión y/o desde las distintas comisiones de vivienda de los barrios. Resultó especialmente relevante la paralización de un desahucio el 1 de diciembre en Torreblanca, con un gran seguimiento por parte del vecindario de este popular barrio que tomó por sorpresa a los activistas más veteranos. Las acciones de este tipo se repetirían durante todo 2012 (figura 2).

Figura 2. Manifestación por la vivienda en Sevilla (2012)

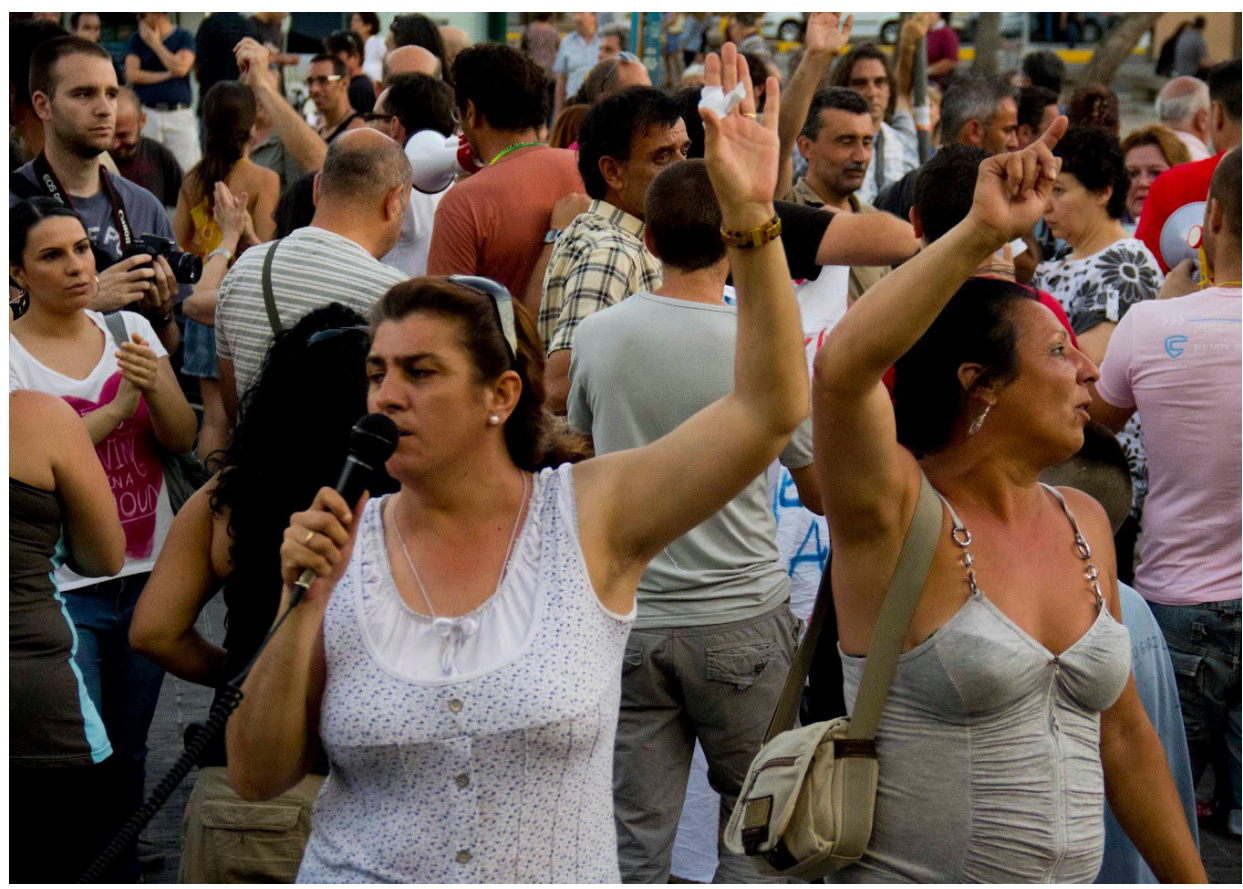

Fte: Anónimo 
A estos comienzos le siguió una fase de consolidación de una estructura mínima del movimiento por la vivienda, dentro de la que es especialmente relevante la conformación de una red de Puntos de Información de Vivienda y Encuentro (PIVEs), gestionados por un abogado y uno o varios activistas de las distintas asambleas del 15M. En febrero de 2012, la Intercomisión convocó una rueda de prensa en la que presentó un informe sobre el volumen y la distribución de los desahucios en la ciudad, anunciando al mismo tiempo el establecimiento de diez PIVEs, que a lo largo del año se incrementarían hasta alcanzar la cifra de 13, repartidos entre los distintos barrios de la ciudad y la primera corona metropolitana. A partir de estas oficinas se empezaron a conformar los primeros grupos de afectados, dentro de los que se encontraban hipotecados amenazados de desahucio, inquilinos que no podían mantener sus alquileres y personas que ya habían sido desahuciadas.

Figura 3. Localización de viviendas subastadas en Sevilla (último trimestre de 2011) y tasas de paro.

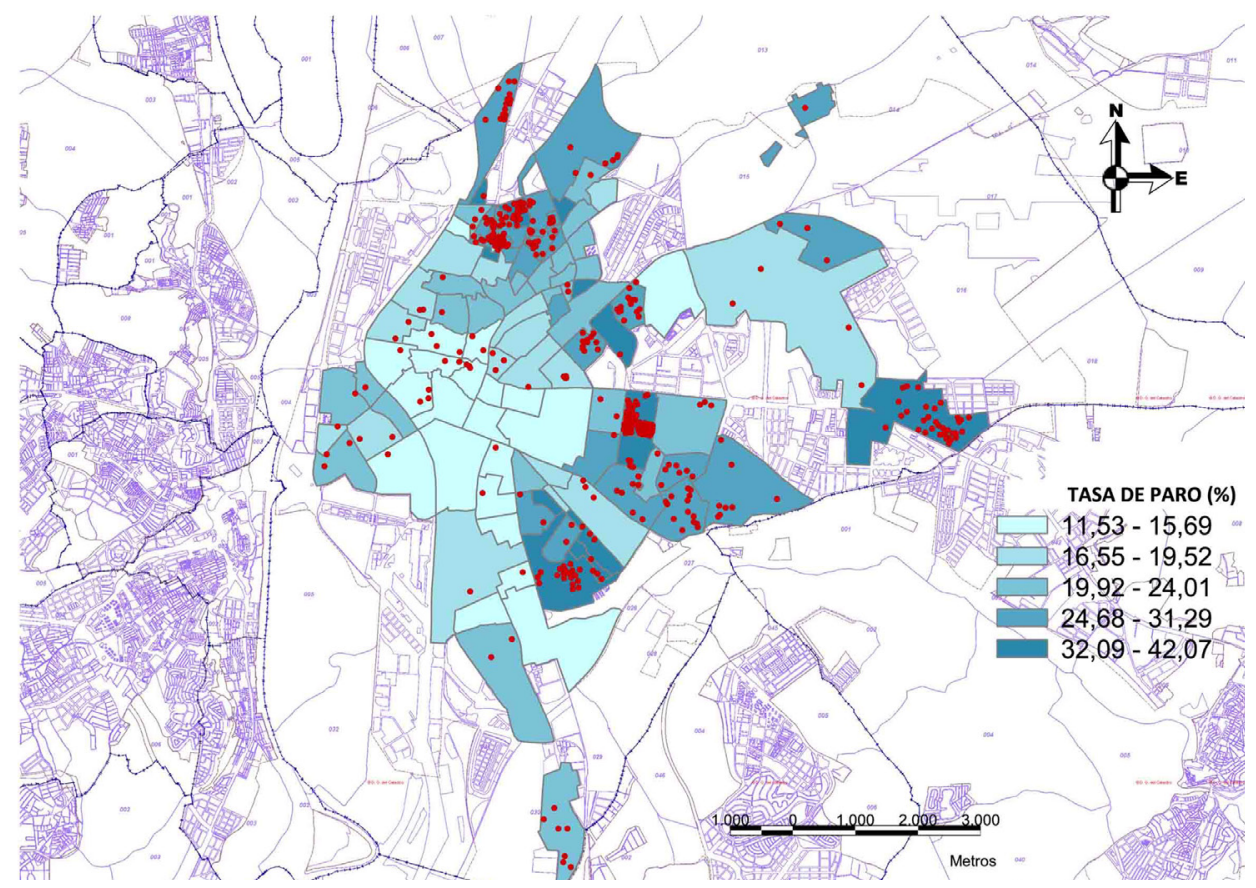

Fte: Elaboración propia a partir de los archivos de la Intercomisión de Vivienda de Sevilla.

La información recogida por la Intercomisión, revela como la incidencia de la problemática recae fundamentalmente sobre los barrios obreros de la ciudad. En la figura 3 puede contemplarse la localización de las viviendas familiares subastadas por entidades crediticias, motivadas por el impago de la hipoteca, en el último trimestre de 2011. Esta información sería recogida como parte del trabajo de campo que daría pie al establecimiento de los PIVEs en toda la ciudad.

El mapa refleja unas pautas de localización de los casos que coinciden fundamentalmente con el semianillo periférico obrero de la ciudad de Sevilla, periferias norte, este y sureste. De forma lógica, el perfil predominante de hogar que acude a los PIVEs es el de una pareja joven, por encima de los 30 años y con cualificación laboral manual media-baja (figura 4). Se trataba mayormente familias con todos sus miembros en 
situación de desempleo, que durante el periodo anterior contaban con salarios estables y suficientes como para poder comprar un piso.

Debido el elevado peso que la lucha por la vivienda adquiere a partir de 2012, las asambleas del $15 \mathrm{M}$ que cobran más fuerza y visibilidad serán, a menudo, aquellas localizadas en estos sectores de mayor afección. El carácter popular de las familias que buscan apoyo y asesoramiento se transmite en primer lugar a los grupos de afectados que se van conformando en los distintos PIVEs y de estos a las asambleas, que en muchos casos sufren un cierto proceso de proletarización, frente al carácter más desclasado del movimiento $15 \mathrm{M}$ original.

Figura 4. Condición sociolaboral de los afectados

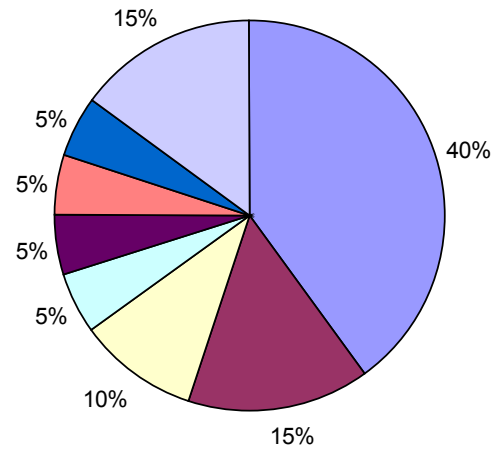

$\square$ Obrero cualificado

$\square$ Obrero no cualificado

$\square$ Empleado comercio

$\square$ Administrativo

- Profesional/ técnico

$\square$ Autonomo

$\square$ Pequeño empresario

$\square$ Desconocido

Fte: Elaboración propia a partir de datos recogidos en 2012 en el PIVE San Pablo.

\subsection{Las Corralas}

Pronto, el movimiento sevillano, aprovechando la intensa experiencia del movimiento okupa en la ciudad, dio un paso más y comenzó las ocupaciones colectivas de edificios vacíos, para el realojo de las familias ya desahuciadas que habían estado organizándose en los grupos de afectados. Así en mayo de 2012, apoyadas principalmente por la asamblea del 15M del distrito Macarena, 38 familias ocuparon 4 edificios deshabitados propiedad de una entidad bancaria, conjunto al que denominaron Corrala "La Utopía". El ejemplo se extendió y el 5 de junio 5 familias ocuparon la Corrala "Conde Quintana", en agosto otras 5 familias ocuparon la Corrala "La Alegría". En los meses siguientes se abrieron tres Corralas más en el municipio de Sevilla y otras cuatro en el área metropolitana, alojando a un total de 145 familias, a las que se sumaron múltiples ocupaciones individuales y no publicitadas que se apoyan en la estructura de PIVEs y de asambleas de barrio del 15M.

Posteriormente el modelo se expandiría a otras ciudades andaluzas, con hasta cuatro ocupaciones masivas en Málaga o con la ocupación de una barriada por 164 familias en Huelva. Por lo general, estas acciones contaron con el apoyo más o menos directo del movimiento $15 \mathrm{M}$. El perfil social es de familias de clase trabajadora con hijos que han perdido sus trabajos y han sido desalojados de sus viviendas, al que se le suma un perfil minoritario de clases medias empobrecidas. Los edificios tomados son, en la mayoría de los casos, bloques residenciales de nueva planta que no habían llegado a ser vendidos, cuya constructora había quebrado y que habían pasado a ser propiedad de una entidad bancaria. 
Figura 3. Ocupación de la Corrala La Utopía.

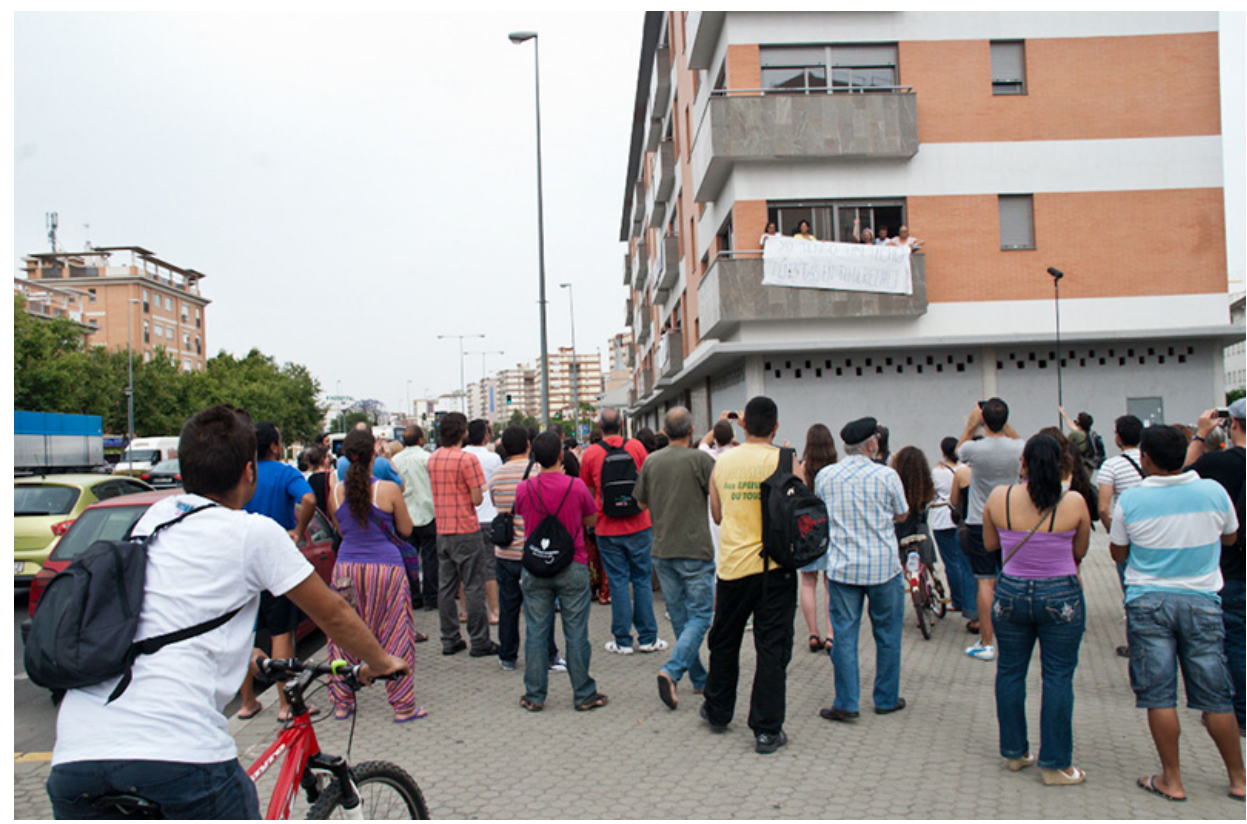

Fte: Sevilla.tomalaplaza.net

Las Corralas, nombre que alude a los viejos patios de vecinos característicos en la ciudad, se convertirán en un elemento característico y diferenciador de las luchas por la vivienda en Sevilla. A escala andaluza, en septiembre de 2012, en los locales de la Corrala Utopía, se organizaron las Jornadas por el Derecho a la Vivienda, en las que se encuentran la Intercomisión de Vivienda del 15M de Sevilla, STOP Desahucios de Córdoba y Granada y la Plataforma de Afectados por la Hipoteca de Málaga, conformando el Movimiento por la Vivienda Digna de Andalucía, con un calendario de movilizaciones y una tabla de reivindicaciones comunes de cara a la administración pública. Alrededor de esas fechas se creó la PAH de Sevilla, surgida a partir de un grupo de afectados en torno al PIVE del distrito Centro. La reivindicación con mayor eco, abanderada por la $\mathrm{PAH}$, ha sido desde el principio el cambio de la ley hipotecaria para permitir la dación en pago. Así, los dos últimos años, la lucha del movimiento por la vivienda ha ido en esta dirección, alcanzando el debate público gran resonancia e instrumentalizando una variedad de tácticas, como los conocidos escraches. El protagonismo de esta demanda, principal punto de consenso del movimiento, ejemplifica tanto la materialidad del problema como la dimensión política de la solución buscada.

En resumen, las ocupaciones realizadas desde 2011 cambian radicalmente su carácter en relación directa a la pauperización y a la problemática concreta de la vivienda provocada por la crisis. Así, en el nuevo movimiento por la vivienda, la acción de la ocupación cuenta con el protagonismo indiscutible de las clases populares, tiene su principal motivación en las necesidades materiales de este grupo y persigue cambios legislativos y políticos que intervengan sobre la situación de precariedad. Esto frente a las tendencias a un activismo desclasado, a motivaciones ideológico-culturales y al rechazo al pacto o concertación con las instituciones del movimiento okupa original (Ver cuadro 1). 
Artículos • Ibán Díaz-Parra

Cuadro 1. Cambios en las características de la ocupación como acción social antes y después de la crisis

\begin{tabular}{|c|c|c|}
\cline { 2 - 3 } \multicolumn{1}{c|}{} & Movimiento okupa & Movimiento por la vivienda-Corralas \\
\hline Composición política & Activismo desclasado & Protagonismo de los grupos populares \\
\hline Motivación & Ideológico-cultural & Necesidad inmediata de vivienda \\
\hline Política institucional & Estilos de vida & $\begin{array}{c}\text { Interlocución/ Búsqueda de cambios } \\
\text { legislativos y políticos }\end{array}$ \\
\hline
\end{tabular}

Fte: Elaboración propia.

\section{Conclusiones}

Este trabajo postula una revisión de los enfoques teóricos sobre movilización social en base al estudio de las luchas relacionadas con el problema de la vivienda y el fenómeno de la ocupación en Sevilla. Estas se han transformado, especialmente desde el inicio de la crisis en 2007, adquiriendo un gran peso las motivaciones materiales.

Los aspectos material-objetivos influyen tanto en el movimiento okupa como en el actual movimiento por la vivienda, aunque lo hacen de forma diversa. Los cambios en la estructura económica a lo largo del siglo XX han modificado la naturaleza del problema urbano y de la vivienda. A su vez, la forma de los movimientos sociales urbanos está condicionada por la configuración coyuntural de la estructura urbana, sin menoscabo de otros factores político-ideológicos.

El caso de la ocupación como acción política desarrollada en un marco reivindicativo ha resultado ser un buen ejemplo de esto. Así, para el movimiento okupa clásico, el contexto material influye como marco de oportunidades, no siendo su movilización y sus objetivos coincidentes con necesidades materiales del grupo y no coincidiendo en ningún momento con una política de clase, ni con una búsqueda de poder político por parte del movimiento. Por lo tanto, la explicación del mismo debe recurrir inevitablemente a aspectos ideológico-culturales, especialmente a la contracultura juvenil, fuertemente identitaria, de la década de los ochenta y noventa en España. Aun así, es evidente la adecuación de estos comportamientos a un contexto de promoción social y afianzamiento de la sociedad del consumo, que convierten la crítica y el cuestionamiento de la propiedad privada en algo marginal.

La evolución posterior de la lucha por la vivienda y la ocupación como forma de acción colectiva viene determinada por factores objetivos, pero también resultan esenciales ciertos aspectos motivacionales. Entre los primeros, la crisis hipotecaria creará una masa de afectados, personas desahuciadas que, motivadas principalmente por su situación personal, darán el salto al activismo emprendiendo acciones de ocupación. Las acciones reivindicativas serán llevadas a cabo de forma pública y colectiva, buscando no solo resolver el problema acuciante de los afectados sino también politizarlo para hacer presión sobre la toma de decisiones o negociar colectivamente.

Por otro lado, el surgimiento del $15 \mathrm{M}$, tanto por las redes de activistas (redes de reclutamiento) creadas por el movimiento, como por su efecto de empoderamiento y legitimación sobre colectivos y activistas que ya venían actuando en torno al 
problema de la vivienda, establecerá un vínculo de colaboración entre activistas y afectados promoviendo la politización de los segundos. Así, el actual movimiento por la vivienda se apoya claramente en las prácticas y discursos generados por "nuevos o novísimos" movimientos sociales, como el okupa o el $15 \mathrm{M}$, y es esa red de activistas existente la que ha hecho posible el paso de los afectados del descontento a la movilización.

A partir del caso estudiado, consideramos que la teoría de los nuevos movimientos sociales cubre agujeros de la teoría marxista que ya habían sido puestos de relieve por otras escuelas de pensamiento e incluso dentro del propio marxismo: fundamentalmente la cuestión sobre el salto hacia la acción colectiva y la involucración de los individuos. Además, amplia el estudio de la acción social a otros actores que no conforman necesariamente una clase social.

Hacer una separación entre modernidad y pos-modernidad en términos de factores materiales y factores ideológico-culturales, entre planteamientos de clase y nuevos movimientos sociales en la movilización social, resulta erróneo. De igual forma, lo es señalar la okupación en el periodo de auge económico como algo exclusivamente cultural-ideológico e ignorar la presencia de estos factores en las movilizaciones desarrolladas a partir de 2007. Aquí, es necesario diferenciar lo que la crítica al marxismo economicista aporta a la teoría y las características que asigna a los movimientos sociales en un contexto dado. Desde la década de los setenta se han cubierto vacíos teóricos sobre la formación de los movimientos. No obstante, no puede olvidarse que estas aportaciones se realizan en el marco concreto de la derrota del movimiento obrero y afianzamiento de la sociedad de consumo en Europa.

La discusión del devenir de la ocupación urbana en Sevilla en relación con el marco teórico, nos confirma que los nuevos movimientos sociales, tal como se introdujo el término en la década de los setenta, se expresan en un contexto de conflictividad baja o no sostenida, elevada promoción social y bienestar material y derrota de los movimientos "antisistema". Se generan dentro del marco limitado y parcial situado entre el fordismo-keynesianismo de posguerra y la progresiva hegemonía neoliberal a partir de la década de los setenta; combinación de condiciones que se ha producido solo una vez en la historia.

Así, cuando la sensación generalizada de progreso se derrumba y se genera malestar material, éste pasa de nuevo a ser una pieza básica de la movilización social, como es el caso de la crisis de 2007. En este sentido, el nuevo contexto y la nueva forma de los movimientos abren la oportunidad para el resurgimiento de políticas de clase que en las décadas anteriores se presentaban como inviables.

\section{Bibligrafía}

Adell, R. (2007). La Vivienda Sí Preocupa. Ocupantes y Okupas. Libre pensamiento, $\mathrm{n}^{\circ}$ 54, 24-31.

Adell, R. y Martínez-López, M. (2004). ¿Dónde Están las Llaves? El Movimiento Okupa: Prácticas y Contextos Sociales. Madrid: Los Libros de la Catarata.

Amin, A. (1994). Postfordism. A Reader. Oxfod: Blackwell.

Agudo, M. (2010). Londres no es Sevilla [Video-Documental]. Sevilla: Intermedia Producciones. 
Borja, J. (Comp.). (1971). Las clases sociales en la sociedad capitalista avanzada. BarceIona: Ediciones de bolsillo.

Berger, P. y Luckmann, T. (1998). Construcción social de la realidad. Argentina: Amorrotu editores.

Bourdieu, P. (1989). El Espacio Social y la Génesis de las Clases. Estudios Sobre las Culturas Contemporáneas, vol. 3, n 7, 27-55.

Calle, A. (2005). Nuevos Movimientos Globales. Hacia la Radicalidad Democrática. Madrid: Popular.

Calle, A. (2013). La Transición inaplazable. Barcelona: Icaria.

Camarero, H. (2009). "Las concepciones de E. P. Thompson acerca de las clases sociales y la conciencia de clase en la historia". Espacios de crítica y producción, $n^{\circ} 40$.

Capel, H. (1983). Capitalismo y morfología urbana. Barcelona: Universidad de Barcelona.

Castells, M. (1974). Movimientos sociales urbanos. México D. F.: Siglo XXI.

Clark, E. (2005). The order and simplicity of gentrification - a political challenge. En Atkinson, R. y Bridge, G. (Eds) Gentrification in a Glboal Context: The new urban colonialism. Oxford: Routledge.

Colau, A. y Alemany, A. (2012). Vidas Hipotecadas. Barcelona: Angle editorial.

Díaz, C. (2003). La Vivienda en España, Reflexiones Sobre un Desencuentro. Scripta Nova. Revista electrónica de geografía y ciencias sociales, vol. 95, nº 146.

Díaz-Parra, I. (2008). Movimientos Vecinales Contra la Gentrificación y Transformaciones en la Política Local de Sevilla. Los Casos del Pumarejo y San Bernardo. Actas X Coloquio internacional de Geocrítica. Barcelona: Universidad de Barcelona.

Díaz-Parra, I. (2009). Procesos de Gentrificación en Sevilla en la Coyuntura Reciente. Scripta Nova: Revista Electrónica de Geografía y Ciencias Sociales, vol. 13, nº 304.

Dieste, J. y Pueyo, A. (2003). Procesos de Regeneración en el Espacio Urbano por las Iniciativas de Autogestión y Okupación. Scripta Nova. Revista electrónica de geografía y ciencias sociales, vol. 108, $\mathrm{n}^{\circ} 146$.

Domínguez, M., Martínez-López, M. y Lorenzi, E. (2010). Okupaciones en Movimiento. Derivas, Estrategias y Prácticas. Madrid: Tierradenadie Ediciones.

Dos Santos, T. (1973). Concepto de Clases Sociales. México D. F.: Ediciones Quinto Sol.

Echeverría, B. (1998). Valor de uso y utopía. México D. F.: Siglo XXI.

Fernández Salinas, V. (1994). Los Centros Históricos en la Evolución de la Ciudad Europea desde los Años Setenta. ERIA, n 74, 121-131.

Fernández, A. y Cruz E. (2013). Análisis Territorial del Crecimiento y la Crisis del Sector de la Construcción en España y la Comunidad Autónoma de Andalucía. Eure, vol. 39, $n^{\circ} 116$.

Goodwin, M. y Painter, J. (1996). Local Governance, the Crises of Fordism and the Changing Geographies of Regulation. Transactions of the Institute of British Geographers, vol. $4, n^{\circ} 2,635-648$.

Gramsci, A. (1949). Los Intelectuales y la Organización de la Cultura. Buenos Aires: Nueva Visión. 
Harvey, D. (1973). Social Justice and the City. Baltimore: Johns Hopkins University Press.

Harvey, D. (1982). The limits to Capital. Oxford: Blackwell.

Harvey, D. (1985). The Urbanization of Capital. Basil Blackwell Ltd, Oxford, 1985

Harvey, D. (1990). The Condition of Postmodernity: An Enquiry into the Origins of Cultural Change. Oxford: Blackwell.

Harvey, D. (2002). Spaces of Hope. Edinburgh: Edinburgh University Press.

Harvey, D. (2007). Espacios del capital. Hacia una Geografía crítica. Madrid: Akal.

Holloway, J. (2002). Change the World Without Taking Power: The Meaning of Revolution Today. London: Pluto Press.

Ibarra, P. (2005). Manual de sociedad civil y movimientos sociales. Madrid: Síntesis.

Jessop, B. (1995). The Regulation Approach, Governance, and Post-Fordism: Alternative Perspectives on Economic and Political Change? Economy and Society, vol. 3, $n^{\circ} 24$, 307-333.

Lasarte-Álvarez, C. (1996). Comentarios a la Ley de Arrendamientos Urbanos. Madrid: Tecnos.

Lefebvre, H. (1969). El Derecho a la Ciudad. Barcelona: Península.

Lenin, V. (1902). ¿Qué Hacer? Stuttgart: Dietz.

López, S. y Sánchez, I. (2005). Los imaginarios de internet: una aproximación crítica a los discursos hegemónicos en el ciberespacio. Nómadas, $n^{\circ} 11$.

Martínez-López, M. (2011). The Struggle for Social Autonomy: What Have We Learnt about Urban Politics from Squatting in Europe? Conference The struggle to belong Dealing with diversity in 21st century urban settings, Amsterdam, Julio.

Martínez-López, M. (2007). El Movimiento de Okupaciones: Contracultura Urbana y Dinámicas Alter-Globalización. Revista de Estudios de Juventud, $n^{\circ} 76$.

Martínez-López, M. (2003). Viviendas y Centros Sociales en el Movimiento de Okupación. Scripta Nova. Revista electrónica de geografía y ciencias sociales, vol. 109, $\mathrm{n}^{\circ}$ 146.

Marsal, M. L. y Vilanova, J. M. (2013) Hegemonía y declive de un ciclo desarrollista ya destronado. Urbanismo y construcción en España 1997-2007. Biblio 3W. Revista Bibliográfica de Geografía y Ciencias Sociales, vol. 18, nº 1015.

Marx, K. y Engels, F. (1848). Manifiesto comunista. Barcelona: Crítica.

Marx, K. (1980). El capital. Crítica de la economía política. Madrid: Siglo XXI.

Melucci, A. (1989). Nomads of the present. Londres: Temple University Press.

Melucci, A. (1999). Acción Colectiva, Vida Cotidiana y Democracia. México: El Colegio de México.

Naredo, J. M. (1998). La Burbuja Inmobiliario-financiera en la Coyuntura Económica reciente. Madrid: Siglo XXI.

Naredo, J. M., Carpintero, O. y Marcos, D. (2008). Patrimonio Inmobiliario y Balance Nacional de la Economía Española (1995-2007). Madrid: Fundación de las Cajas de Ahorro Confederadas. 
Ossowski, S. (1972). Estructura de Clases y Conciencia Social. Buenos Aires: Editorial Diez.

Pastor, J. (2006). Los movimientos sociales. De la crítica de la modernidad a la denuncia de la globalización. En Intervención Psicosocial, vol. 15, n² 2, 133-147.

Poulantzas, N. (1976). Las Clases Sociales en el Capitalismo Actual. México D. F. : Siglo $X X I$.

Pruijt, H. (2003). Is the Institutionalization of Urban Movements Inevitable? A Comparison of the Opportunities for Sustained Squatting in New York City and Amsterdam. International Journal of Urban and Regional Research, vol. 1, n² 27, 133-157.

Rodríguez López, E. y López Hernández, I. (2011). Del auge al colapso. El modelo financiero-inmobiliario de la economía española (1995-2010). Revista de Economía Crítica, $n^{\circ} 12$.

Sargatal, M. A. (2003). La Vivienda en el Centro Histórico de Barcelona. El caso de la Rambla del Raval. Scripta Nova, vol. 7, nº 146.

Sguiglia N. y Fernánez, S. (Eds). (2008). Autonomía y metrópolis. Del movimiento okupa a los centros sociales de segunda generación. Malaga: Universidad Libre Experimental/ Cedma.

Soja E. W. (2001). Postmetropolis. Critical Studies of Cities and Regions. Oxford: Blackwell.

Tezanos, J. F. (1984). Cambio social y modernización en la España actual. REIS, $n^{\circ} 28$, 19-61.

Tezanos, J. F. (2002). Desigualdad y exclusión social en las sociedades tecnológicas. Revista del Ministerio de Trabajo y asuntos sociales, $n^{\circ} 35,35-53$.

Thompson, E. P. (2012). La formación de la clase obrera en Inglaterra. Madrid: Capitan Swing.

Tomé, S. (2007). Los Centros Históricos de las Ciudades Españolas. Ería, nº 72, 75-88.

Topalov, C. (2006). La Urbanización Capitalista. Algunos Elementos para su Análisis. Buenos Aires: Universidad de Buenos Aires.

Touraine, A. (1973). La imagen histórica de la sociedad de clases. Buenos Aires: Nueva Visión.

Scott, J. C. (2003). Los dominados y el arte de la resistencia. Tafalla: Txalaparta.

VVAA. (2007). Madrid ¿La suma de todos? Globalización, territorio, desigualdad. Madrid: Traficantes de Sueños.

VVAA. (2006). El gran pollo de la Alameda. Sevilla: Colectivo redactor, Sevilla. 